\title{
An Overview of Power Electronics in Electric Vehicles
}

\author{
C. C. Chan, Fellow, IEEE, and K. T. Chau, Member, IEEE
}

\begin{abstract}
In response to concerns about energy cost, energy dependence, and environmental damage, a rekindling of interest in electric vehicles (EV's) has been obvious. Based on the "California rules" on zero emission vehicles in the United States, as well as similar tightened air pollution regulation in Europe, Asia, and much of the rest of the world, the market size of EV's will be enormous. Thus, the development of power electronics technology for EV's will take an accelerated pace to fulfill the market needs. This paper reviews the current status of multidisciplinary technologies in EV's. Various challenges of power electronics technology for EV propulsion, battery charging, and power accessories are explored.
\end{abstract}

Index Terms-Electric vehicles, power electronics.

\section{INTRODUCTION}

$\mathbf{I}^{\mathrm{N}}$ $\mathrm{N}$ THE EARLY 1900's, three types of automobiles-electric, steam, and gasoline-were competing with each other. Yet, within little more than a decade, technology innovation and the public's thirst for speed and power on the road sealed transportation's future behind the wheels of gasoline-powered automobiles for nearly the next hundred years.

The 1990's appear to be the decade in which what goes around comes around. The societal reasons for the revival of electric vehicles (EV's) are the monetary cost of energy and its cost in national dependence, coupled with the more recent focus on the environmental damage inflicted by internal combustion engines. Gasoline-powered vehicles have been targeted as a major source of the emissions that create urban air pollution, accounting for $43 \%$ of nonmethane organic gases (NMOG) emissions, $57 \%$ of nitrogen oxides $\left(\mathrm{NO}_{x}\right)$ emissions, and $82 \%$ of carbon monoxide (CO) emissions [1]. Emissions associated with EV's come from generating the electricity to charge EV batteries, rather than from operating the vehicles. However, even in a worst-case scenario-a generation mix that emphasizes the use of coal-these emissions are generally much lower than those associated with operating gasolinepowered vehicles. Assuming U.S. 1995 emission standards for conventional vehicles and the 1995 generation mix for a typical urban area, replacing a conventional vehicle with an $\mathrm{EV}$ can greatly reduce emissions-NMOG by $98 \%, \mathrm{NO}_{x}$ by $92 \%$, and CO by $99 \%$. Moreover, as the majority of electricity generation plants are located outside urban areas, the people

Manuscript received January 11, 1996; revised February 22, 1996.

The authors are with the Department of Electrical and Electronic Engineering, University of Hong Kong, Hong Kong.

Publisher Item Identifier S 0278-0046(97)00067-1. living and working in cities are not exposed to plant-related emissions [2].

In October 1990, the California Air Resources Board established rules that mandate $2 \%$ of all vehicles sold in California in 1998 must be zero emission vehicles (ZEV's) and by 2003, the ZEV sales quota will be $10 \%$. On October 29, 1991, nine other states and the District of Columbia in the U.S. adopted these "California rules." This virtually guarantees that American consumers will buy approximately 290000 EV's in 2001. If the other states adopt the same rules, EV sales in 2001 will be mandated to be almost 850000 [3]. Moreover, Europe, Asia, and much of the rest of the world are no less motivated. Roughly, the EV market size all over the world in 2001 can be estimated to be 1.5 million.

Power conversion and control functions form the basis of what has come to be known as the field of power electronics [4]. In recent years, power electronics technology has been spurred by needs for efficient control of motors in industrial drives and the development of more reliable lightweight switching power supplies for sophisticated computer and communication equipment [5]. In response to technological needs for EV's, the development of power electronics technology will take an accelerated pace in future years.

The revival of EV's is becoming more and more definite. This opinion is not only found in technical literature [6]-[8], but also in business magazines [9]. Based on our previous work [10], the purpose of this paper is to review the current status of multidisciplinary EV technologies and to explore various challenges of power electronics technology in EV's. In Section II, the concept of multidisciplinary technologies is described. Power electronics in EV propulsion, battery charging, and power accessories are described in Sections III-V, respectively. The concept of system integration in EV's is briefed in Section VI. The flagship EV's of GM (the Impact 4), Nissan (the FEV), and BMW (the E1/E2), as well as the U2001, jointly developed by the University of Hong Kong, Amerigon, and Honda, are compared in Table I to illustrate the latest EV technologies.

\section{MultidisCIPLINARY TEChNOLOGIES}

The technologies involved in EV's are diversified and include electrical and electronics engineering, mechanical and automotive engineering, and chemical engineering. Specialists in these disciplines of engineering must work together and pool their knowledge in the main areas that must be integrated: body design, batteries, electric propulsion, and intelligent energy management. 
TABLE I

CoMPaRison of LATEST EV TEChNOLOGIES

\begin{tabular}{|c|c|c|c|c|}
\hline & GM Impact 4 & Nissan FEV & BMW E1/E2 & $\mathrm{U} 2001$ \\
\hline Curb weight (kg) & 1348 & 900 & 915 & 1973 \\
\hline Drag coefficient & 0.185 & 0.19 & 0.32 & 0.34 \\
\hline Rolling coefficient & 0.0048 & 0.005 & 0.008 & 0.0044 \\
\hline Top speed $(\mathrm{km} / \mathrm{h})$ & 128 (governed) & 130 & $120(\mathrm{E} 1)$ & 110 \\
\hline Acceleration $(\mathrm{km} / \mathrm{h}, \mathrm{s})$ & $0 \rightarrow 96,8.5$ & $0 \rightarrow 40,3.6$ & $0 \rightarrow 50,6(\mathrm{E} 1)$ & $0 \rightarrow 48,6.3$ \\
\hline Range (km@km/h) & $193 @ 89^{\dagger}$ & $160 @ 72$ & $155 @ 80(\mathrm{E} 1)$ & $176 @ 88$ \\
\hline Battery type & Pb-Acid & $\mathrm{Ni}-\mathrm{Cd}$ & $\mathrm{Na}-\mathrm{S}$ & $\mathrm{Ni}-\mathrm{Cd}$ \\
\hline Battery weight $(\mathrm{kg})$ & $395^{\dagger}$ & 200 & 265 & 792 \\
\hline Voltage level (V) & 312 & 280 & 180 & 264 \\
\hline Energy capacity $(\mathrm{kWh})$ & 16.8 & 11.6 & 28.8 & 37 \\
\hline Motor type & $\begin{array}{l}\text { Induction } \\
\text { motor }\end{array}$ & $\begin{array}{l}\text { Dual induction } \\
\text { motors }\end{array}$ & $\begin{array}{l}\text { PM brushless } \\
\text { DC motor }\end{array}$ & $\begin{array}{l}\text { PM brushless } \\
\text { DC motor }\end{array}$ \\
\hline Transmission type & Planetary gear & Planetary gear & Planetary gear & Planetary gear \\
\hline Converter type & $\begin{array}{l}\text { IGBT-based } \\
\text { inverter }\end{array}$ & $\begin{array}{l}\text { IGBT-based } \\
\text { inverter }\end{array}$ & $\begin{array}{c}\text { MOSFET/IGBT } \\
\text {-based inverter }\end{array}$ & $\begin{array}{l}\text { IGBT-based } \\
\text { inverter }\end{array}$ \\
\hline
\end{tabular}

${ }^{\dagger}$ Old version of GM Impact

\section{A. Body Design}

There are two basic methods for producing EV's-either convert or build for purpose. For the conversion method, the engine and associated equipment of an existing vehicle are replaced by the electric motor, controller, and batteries. This offers some economy because the whole vehicle is already there and the purchase price is quite low. However, in most conversions, the resulting $\mathrm{EV}$ has a greater curb weight and may have a higher center of gravity and/or other weight distribution differences that can affect handling. Purpose-built or ground-up EV's have more advantages than conversions. In designing an EV from the ground up, the engineers have the opportunity to integrate various components so that they work most efficiently together [11]. Manufacturers are now investing in the design of EV's from the ground up, such as the GM Impact 4, Nissan FEV, and BMW E1/E2 [12]-[14].

There are some design concepts which are particularly important for purpose-built EV's. These concepts include the consistent weight-saving design, optimum safety concept, low drag coefficient body design, and low rolling resistance concept. As shown in Table I, the curb weight, drag coefficient, and tire rolling resistance coefficient of the latest EV's are given. The top speed, acceleration, and range of these EV's are also given. It should be noted that the drag coefficient of 0.185 is almost the lowest figure among present EV's, and the tire rolling resistance coefficient of 0.005 is about $40 \%$ that of conventional tires.

\section{B. Batteries}

Because the specific energy and specific power of electrochemical batteries are generally much smaller than those of gasoline, a large number of batteries are required to assure a desired level of power performance. However, mounting a vehicle with a large number of batteries suffers from several shortcomings: the reduction of interior and luggage spaces, the increase in vehicle weight and cost, and the degradation of vehicle performance. Thus, the development of battery technology has been accelerated, in which a set of criteria including the specific energy, specific power, energy efficiency, charging rate, cycle life, operating environment, cost, safety, and recycling must be considered.

Until now, the most mature battery technology suitable for EV's has been lead-acid ( $\mathrm{Pb}-\mathrm{Acid})$. Among various advanced batteries, nickel-based batteries such as nickel-iron $(\mathrm{Ni}-\mathrm{Fe})$, nickel-cadmium (Ni-Cd), and nickel-metal hydride (Ni-MH) have received heightened interest. On the other hand, zinchalogen batteries such as zinc-bromine $(\mathrm{Zn}-\mathrm{Br})$ and hightemperature batteries such as sodium-sulfur $(\mathrm{Na}-\mathrm{S})$ are also attractive. Recent commercially available batteries for EV's are listed in Table II, where the specific power is recorded at $80 \%$ of depth-of-discharge (DOD) and the cycle life is at $100 \%$ of DOD [15]-[19].

The battery type, weight, voltage level, and energy capacity of the latest EV's are also given in Table I. Until now, $\mathrm{Pb}-\mathrm{Acid}$ batteries are the most popular in EV's such as the GM Impact 4, EPRI/GM G-Van, Mazda Bongo, Suzuki Cervo, Daihatsu Hijet, Mitsubishi Mini-Cab, and Nissan EV Guide II. Ni-Cd batteries are also commonly used in EV's,such as the Nissan FEV, U2001, Renault Zoom, and Tepco IZA. Na-S batteries are used in the BMW E1/E2, Ford Ecostar, and LADWP/SCE LA301. Ni-Fe batteries are used in the EPRI/Chrysler TEVan and Nissan March EV-II. $\mathrm{Zn}-\mathrm{Br}$ batteries are used in the Toyota EV-40.

Many researchers are excited by the idea of coupling electrochemical batteries with electric flywheels or ultracapacitors which can deliver surges of power. Recently, an ultrahighspeed flywheel, known as an electromechanical battery (EMB), 
TABLE II

COMPARISON OF LATEST EV BATTERIES

\begin{tabular}{c|c|c|c|c|c|c|c}
\hline & Manufacturer & Model & $\begin{array}{c}\text { Weight } \\
(\mathrm{kg})\end{array}$ & $\begin{array}{c}\text { Capacity } \\
(\mathrm{Ah})\end{array}$ & $\begin{array}{c}\text { Specific } \\
\text { energy } \\
(\mathrm{Wh} / \mathrm{kg})\end{array}$ & $\begin{array}{c}\text { Specific } \\
\text { power } \\
(\mathrm{W} / \mathrm{kg})\end{array}$ & $\begin{array}{c}\text { Cycle } \\
\text { life }\end{array}$ \\
\hline $\mathrm{Pb}$-Acid & Johnson Controls & GC 12550 & 18.6 & 37 & 23.7 & 120 & 500 \\
$\mathrm{~Pb}-$ Acid & Sonnenschein & DF 6V 180 & 30.2 & 150 & 29.3 & $80-100$ & 700 \\
$\mathrm{~Pb}-\mathrm{Acid}$ & Electrosource & Horizon & 27 & 112 & 50 & $>300$ & 900 \\
$\mathrm{Ni}-\mathrm{Cd}$ & SAFT & STM 5.140 & 23.2 & 136 & 45.3 & 260 & 2000 \\
$\mathrm{Na}-\mathrm{S}$ & ABB & B-11 & 253 & 238 & 81 & 152 & 600 \\
$\mathrm{Na}-\mathrm{S}$ & Silent Power & PB-MK3 & 29.2 & 292 & 79 & 90 & 800 \\
$\mathrm{Ni}-\mathrm{MH}$ & Ovonics & OBC & 17.1 & 100 & 80 & 245 & 1000 \\
$\mathrm{Ni}-\mathrm{Fe}$ & Eagle-Picher & NIF 200 & 25 & 203 & 51 & 99 & 920 \\
$\mathrm{Zn}-\mathrm{Br}$ & Sea & ZBB-5/48 & 81 & 126 & 79 & 40 & 350 \\
\hline
\end{tabular}

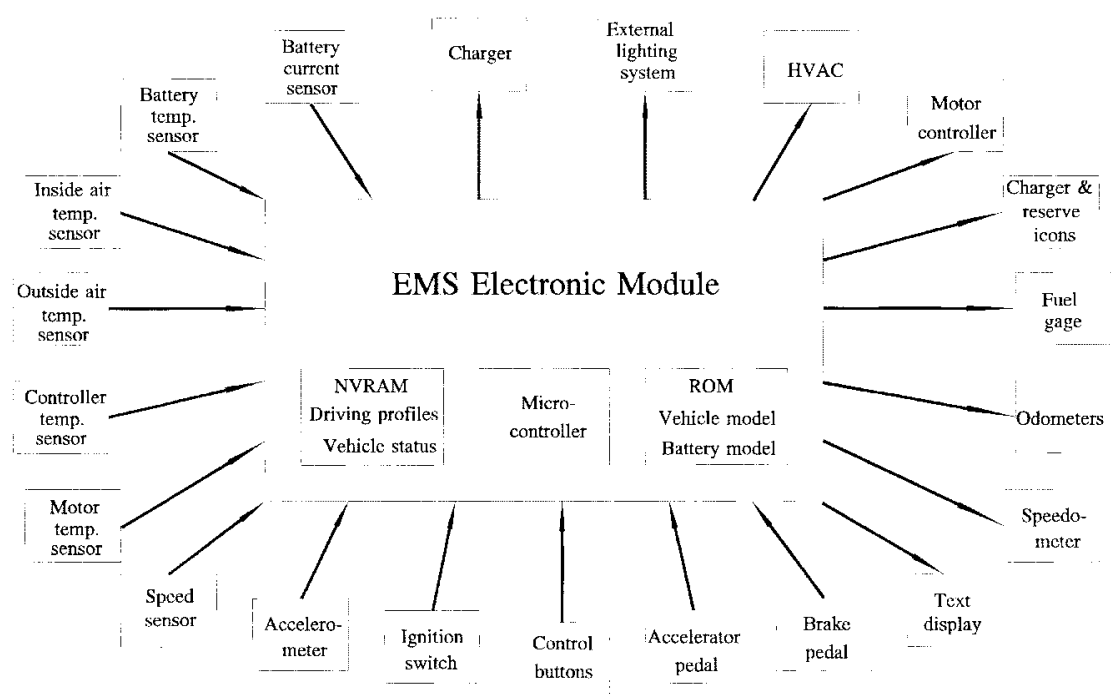

Fig. 1. Functional block diagram of energy management system.

has been reported [20]. This EMB can deliver a whooping $5000-10000 \mathrm{~W} / \mathrm{kg}$, which is orders of magnitude higher than anything achievable by an electrochemical battery or even an internal combustion engine.

\section{Electric Propulsion}

Electric propulsion is to interface electric supply with vehicle wheels, transferring energy in either direction as required, with high efficiency, under control of the driver at all times. From the functional point of view, an electric propulsion system can be divided into two parts-electrical and mechanical. The electrical part includes the motor, power converter, and electronic controller. On the other hand, the mechanical part consists of the transmission device and wheels. Sometimes, the transmission device is optional. The boundary between electrical and mechanical parts is the air-gap of the motor, where electromechanical energy conversion is taking place.

Electric propulsion, a major power electronics area, plays a very important role in EV's. Sometimes, it is described as the heart of EV's. This important area and its corresponding challenges in EV's are detailed in Section III.

\section{Intelligent Energy Management}

Maximizing energy usage and monitoring energy capacity are critical to attaining acceptable performance in EV's. As shown in Fig. 1, the energy management system (EMS) making use of sensory inputs from subsystems of the vehicle predicts range for standardized driving profiles, controls the energy usage of vehicle subsystems, suggests more energyefficient driving behavior, directs regenerated energy from braking to batteries, selects battery charging algorithm based on battery state-of-charge and cycle life history, modulates climate control in response to current driving conditions, and adjusts lighting brightness in response to available external light intensity. When the EMS is coupled with a navigation system, it can plan energy efficient routes, locate charging facilities for extended trips, and modify range prediction and energy efficiency of route predictions on the basis of traffic conditions. 


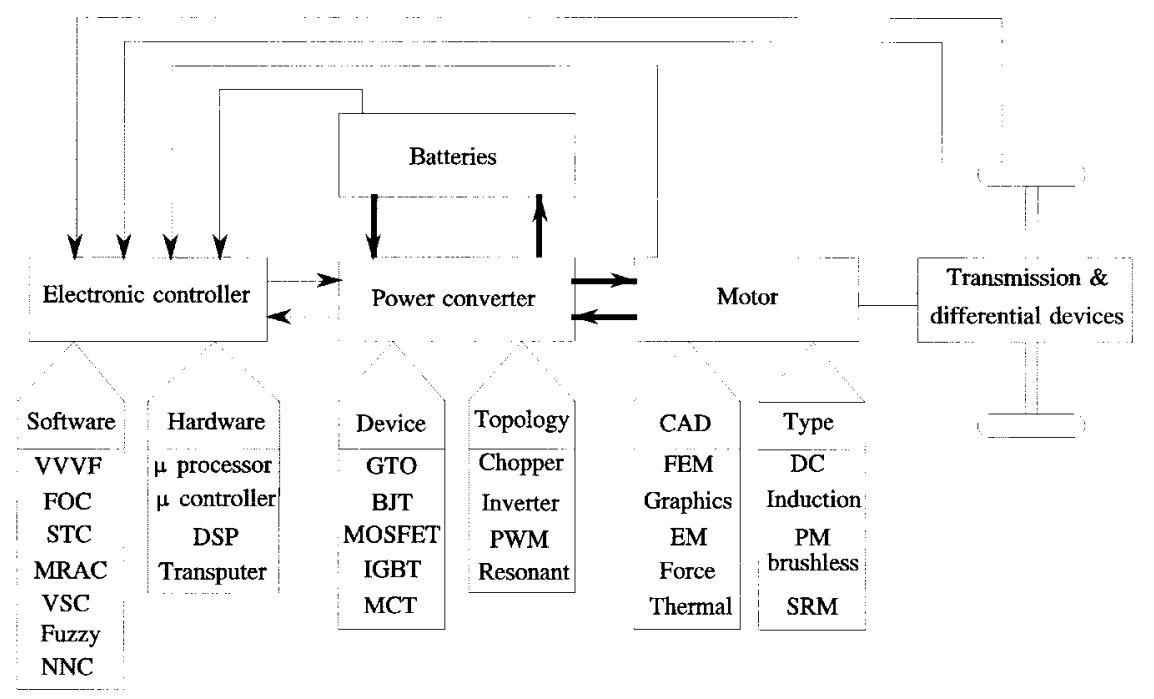

Fig. 2. Functional block diagram of EV propulsion system.

\section{EV PROPULSION}

Fig. 2 illustrates the functional block diagram of a typical EV propulsion system where the arrow-headed thick and thin lines represent the power and signal flows, respectively. Due to the availability of regenerative braking, the power flow is reversible. Depending on the motor control strategy, driver's command, and data obtained from the EMS, the electronic controller provides proper control signals to the power converter. These signals are amplified via a driving circuitry to switch proper power devices. Thus, the power converter regulates power flow between batteries and the motor during motoring and regenerative braking. Finally, the motor interfaces with wheels via the transmission device. Instead of using a single motor, the use of multiple motors, generally either two or four, has also been used for EV propulsion. Fig. 3 illustrates the single-motor and dual-motor propulsion configurations. The major difference is the elimination of mechanical transaxle differentials in the single-motor configuration, while the differential action in the multiplemotor configuration is carried out electronically. Since these two configurations have their individual merits, both of them have been employed by modern EV's. As given in Table I, the GM Impact 4, BMW E1/E2, and U2001 employ the single-motor configuration, while the Nissan FEV adopts the dual-motor configuration.

\section{A. Motors}

Electric motors have been available for over a century. The evolution of motors, unlike that of electronics and computer science, has been long and slow. Nevertheless, the development of motors is continually fueled by high-energy permanent magnets (PM's), sophisticated motor topologies, and powerful computer-aided design (CAD) techniques.

PM's provide motors with lifelong excitation. The only outlay is the initial cost which is reflected by the price of motors. Apart from ferrites, alnico, and samarium-cobalt ( $\mathrm{Sm}-\mathrm{Co}$ ), neodymium-iron-boron ( $\mathrm{Nd}-\mathrm{Fe}-\mathrm{B})$ PM's have been introduced. Because of their highest remanence and coercivity as

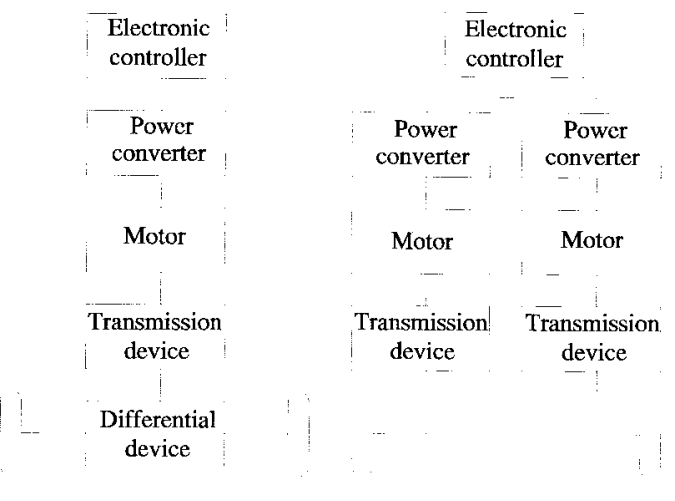

(a)

(b)

Fig. 3. Single-motor and dual-motor configurations.

well as reasonable low cost, $\mathrm{Nd}-\mathrm{Fe}-\mathrm{B}$ PM's have promising applications to motors. In fact, adopting these "super magnets," a number of new motor topologies with high power density and high efficiency have recently been developed [21].

Traditional dc commutator motors, loosely named as dc motors, have been prominent in EV propulsion. Their control principle is simple. By replacing the field winding and pole structure with high-energy PM's, PM dc motors permit a considerable reduction in stator diameter. Owing to the low permeability of PM's, armature reaction is usually reduced and commutation is improved. However, the principal problem of dc motors arises from their commutators and brushes which makes them less reliable and unsuitable for maintenance-free operation.

Recent technological developments have pushed ac motors to a new era, leading to definite advantages over dc motors: higher efficiency, higher power density, lower cost, more reliable, and almost maintenance free. As high reliability and maintenance-free operation are prime considerations in $\mathrm{EV}$ propulsion, ac induction motors are becoming attractive [22]. However, conventional control of induction motors such as variable-voltage variable-frequency (VVVF) cannot provide the desired performance of EV's [23]. One major reason is 


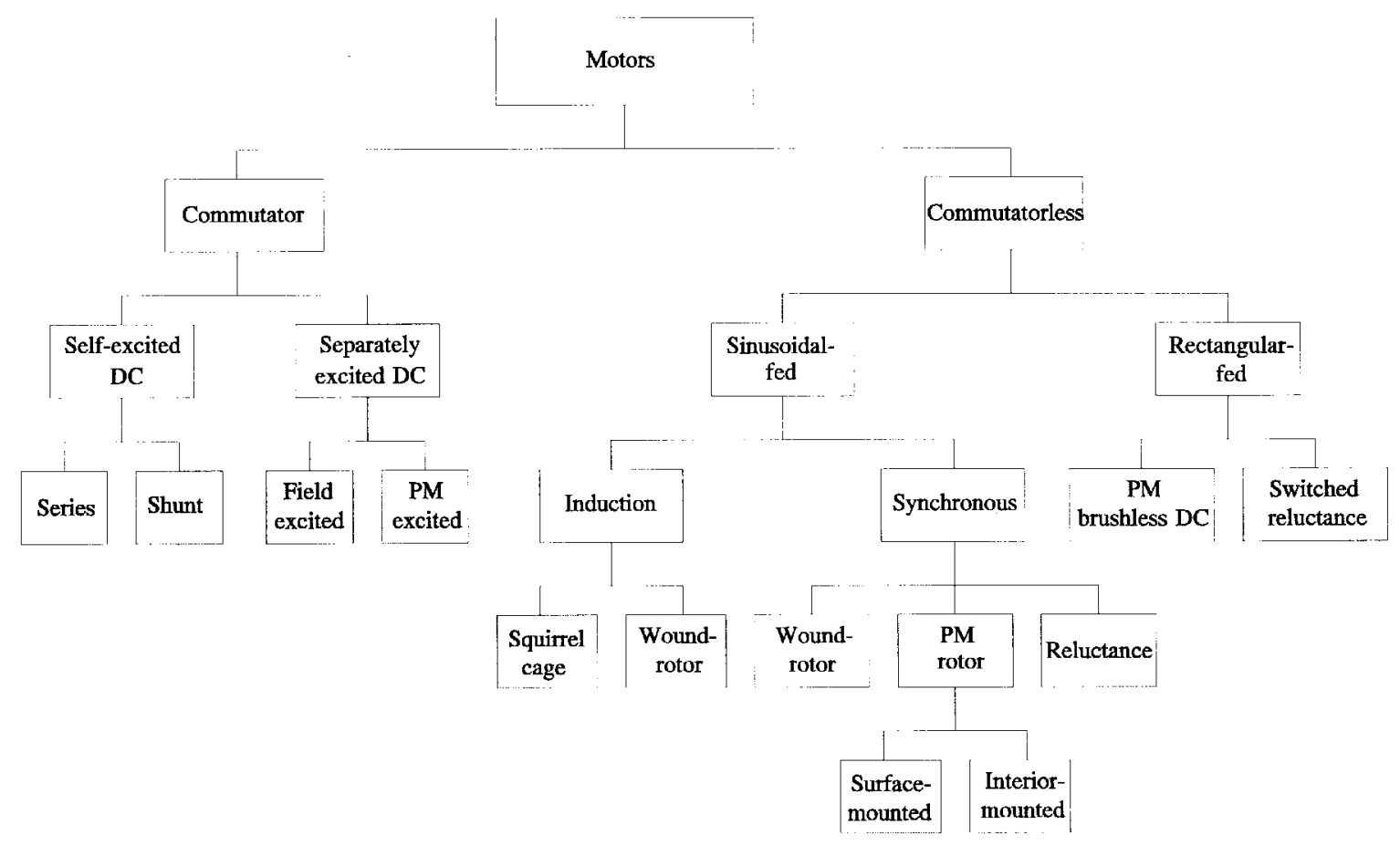

Fig. 4. Classification of EV propulsion motors.

due to the nonlinearity of its dynamic model with coupling between direct and quadrature axes. With the advent of the microcomputer era, the principle of field-oriented control (FOC) of induction motors is becoming accepted [24].

By replacing the field winding with high-energy PM's, PM synchronous motors can eliminate conventional brushes, sliprings, and field copper losses. As these motors are essentially traditional ac synchronous motors with sinusoidal-distributed windings, they can run from a sinusoidal or PWM supply without electronic commutation. When PM's are mounted on the rotor surface, they behave as nonsalient synchronous motors because the permeability of PM's is similar to that of air. On the other hand, by burying PM's inside the magnetic circuit of the rotor, the saliency causes an additional reluctance torque which leads to provide a wide speed range at constant power operation [25].

By inverting the stator and rotor of PM dc motors, rectangular-fed ac motors, so-called PM brushless dc motors, are generated. The most obvious advantage of these motors is the removal of brushes, leading to the elimination of many problems associated with brushes. Another advantage is the ability to produce a larger torque at the same peak current and voltage because of the interaction between rectangular current and rectangular magnetic field [26], [27]. Moreover, the brushless configuration allows more cross-sectional area available for the armature winding, thus facilitating the conduction of heat through the frame and, hence, increasing the electric loading and power density. Although their configurations are very similar to those of PM synchronous motors, there is a distinct difference in that PM brushless dc motors are fed by rectangular ac wave, while PM synchronous motors are fed by sinusoidal or PWM ac wave.
Switched reluctance motors, though the principle of which has been known for over a century, have seen a revival of interest in recent years. Basically, they are direct derivatives of single-stack variable-reluctance stepper motors, in which the current pulses are phased relative to the rotor position to optimize operation in the continuous rotation mode. Similar to PM brushless dc motors, they usually require shaft position sensors. However, switched reluctance motors suffer from the same excitation penalty as induction motors, and cannot attain the efficiency or power density of PM ac motors.

To keep up with the more stringent design requirements and fast-changing motor topologies, the design of EV propulsion motors turns to CAD. The finite element method (FEM) outranks other numerical methods because of its applicability in electromagnetic, force, and thermal analyses [28], [29]. Moreover, computer graphics and distributed computing have also been employed for the design [30], [31].

A typical classification of EV propulsion motors is illustrated in Fig. 4 where the shaded motor types have been accepted for modern EV's. As given in Table I, both the GM Impact 4 and Nissan FEV employ the induction motor, while both the BMW E1/E2 and U2001 use the PM brushless dc motor. Fig. 5 shows the dual induction motors in the Nissan FEV with a rated output of $20 \mathrm{~kW}$ and starting torque of 95.5 $\mathrm{N} \cdot \mathrm{m}$ [32], as well as the Unique Mobility PM brushless dc motor in the BMW E1 with $32 \mathrm{~kW}$ and $150 \mathrm{~N} \cdot \mathrm{m}$ [14]. On the other hand, the other motor types are also employed in EV's such as the PM synchronous motor in the Ford/GE ETX-II, the switched reluctance motor in the Chloride Lucas, the dc series motor in the Daihatsu Hijet, the dc shunt motor in the Mazda Bongo, the dc separately excited motor in the Fiat 900E/E2, and the PM dc motor in the Suzuki Senior Tricycle. 


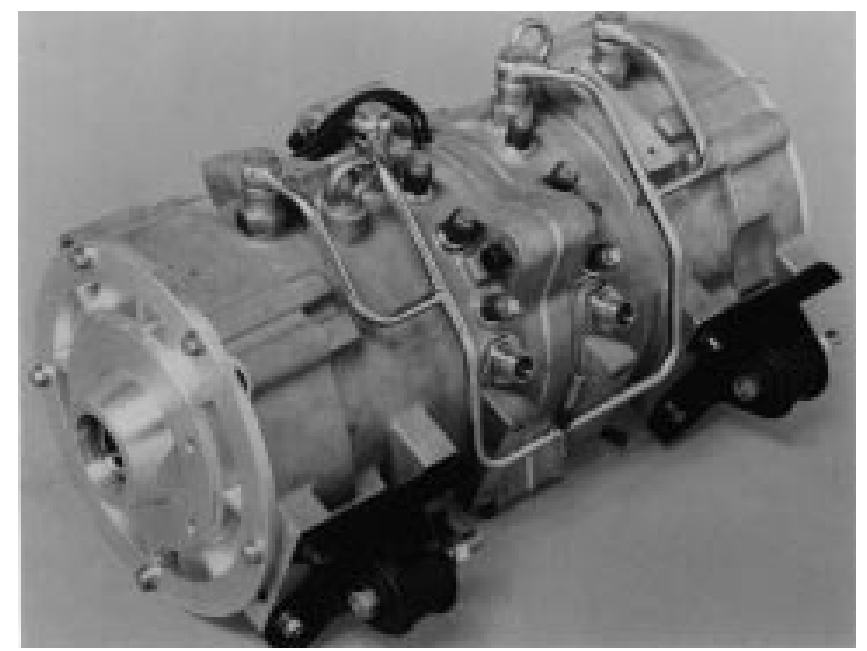

(a)

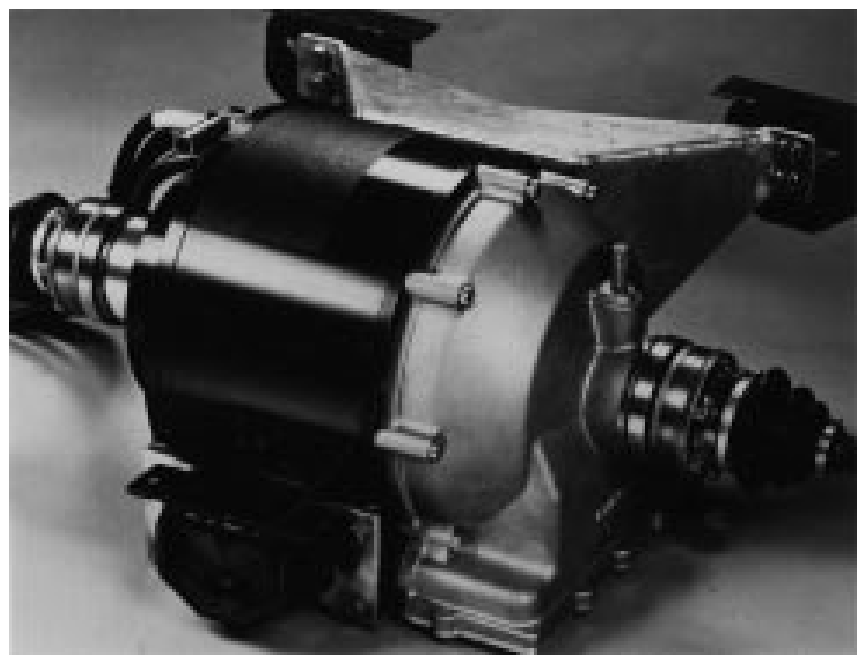

(b)

Fig. 5. Advanced EV propulsion motors: (a) dual induction motors in Nissan FEV and (b) PM brushless de motor in BMW E1.

The use of conventional gearing as the transmission device can no longer satisfy the needs of EV's. Recently, planetary gearing has been accepted as the transmission device of the latest EV's such as the GM Impact 4, Nissan FEV, BMW E1/E2, and U2001 because it offers high gear ratio and high transmission efficiency. The planetary gear set of the Nissan FEV is 12:1, while the ratio of the U2001 is 11:1. By using planetary gearing, the concept of motorized wheels can be easily realized [33]. On the other hand, by abandoning the transmission device or gearing these motorized wheels can be realized directly using outer rotor wheel motors. Recently, the Tepco IZA has employed four gearless motorized wheels, where each of them is an outer rotor PM brushless dc motor of $6.8 \mathrm{~kW}$ at $288 \mathrm{rpm} \mathrm{[34].}$

\section{B. Power Converters}

In the past few years, power device technology has made tremendous progress. These power devices have grown in power rating and performance by an evolutionary process. The recently introduced power devices are the gate-turnoff thyris- tor (GTO), power bipolar-junction transistor (BJT), power metal-oxide field-effect transistor (MOSFET), insulated-gate bipolar transistor (IGBT), static-induction transistor (SIT), static-induction thyristor (SITH), and MOS-controlled thyristor (MCT). Active research is still being pursued on the development of high-performance power devices. The selection of power devices for EV propulsion is generally based on the requirements of the voltage rating, current rating, switching frequency, power loss, and dynamic characteristic. The voltage rating depends on the battery nominal voltage, maximum voltage during charging, and maximum voltage during regenerative braking. The current rating depends on the motor peak power rating and number of devices connected in parallel. The switching frequency should be high enough to reduce the acoustic noise, size of filters, and EMI problem. On the other hand, higher switching frequencies increase the switching loss. Since an extra 1\% efficiency in EV propulsion can enable an additional few miles in the EV driving range, the power loss including both switching and conduction losses should be minimum. The dynamic characteristic should be good enough to allow for high $d v / d t$ capability, high $d i / d t$ capability, simple driving, and easy paralleling. The device protection, packaging, reliability, and cost should also be considered.

Among the available power devices, the GTO, BJT, MOSFET, IGBT, and MCT are particularly suitable for EV propulsion [35]. Some of their operating characteristics are given in Table III. At present, the IGBT is the most attractive because it possesses high input impedance and the highspeed characteristics of a MOSFET with the conductivity characteristic of a BJT. In the near future, the MCT will be a good candidate for EV propulsion because it combines high switching speed, high power handling capability, superior dynamic characteristic, and high reliability [36]. Fig. 6 shows an advanced IGBT-based inverter in the Nissan FEV with a maximum output of $60 \mathrm{kVA}$ and switching frequency of 10 $\mathrm{kHz}$ [32]. Recently, a MCT-based inverter with $87.3 \mathrm{kVA}$ and $5 \mathrm{kHz}$ has been tested by the Ford/GE ETX-II. This MCT-based inverter is only $45 \%$ of the BJT-based inverter volume and weighs $28 \%$ less than the BJT-based inverter [37].

The evolution of power converter topologies normally follows that of power devices, aiming to achieve high power density, high efficiency, and robust power converters. dc-dc converters (dc choppers) and dc-ac converters (inverters) are employed for $\mathrm{dc}$ and ac motors, respectively. In addition to conventional pulsewidth modulated (PWM) inverters, one of the latest inverter topologies for battery-fed applications is so-called resonant dc-link inverters. These resonant dc-link inverters have either a parallel or series resonant circuit, thus providing either zero-voltage-switching (ZVS) or zero-currentswitching (ZCS) condition. Outweighing the additional cost due to the resonant tank and increased control complexity, they have the advantages of zero switching loss, low heat sinking requirement, snubberless operation, high power density, less severe EMI problem, very small acoustic noise, and improved reliability. Because of these merits, resonant dc-link inverters have promising applications to EV propulsion. 
TABLE III

Comparison of Latest Power Devices for EV Propulsion

\begin{tabular}{c|c|c|c|c|c|c}
\hline & $\begin{array}{c}\text { Power } \\
\text { capability } \\
(\mathrm{V}, \mathrm{A})\end{array}$ & $\begin{array}{c}\text { Linear/ } \\
\text { trigger }\end{array}$ & Gating & $\begin{array}{c}\text { Conduction } \\
\text { drop }\end{array}$ & $\begin{array}{c}\text { Drop } \\
\text { sensitivity } \\
\text { with }{ }^{\circ} \mathrm{C}\end{array}$ & $\begin{array}{c}\text { Switching } \\
\text { frequency } \\
\text { (kHz) }\end{array}$ \\
\hline GTO & 5000,3000 & Trigger & Current & Medium & Negative & Low \\
BJT & 1400,800 & Linear & Current & Low & Negative & Medium \\
MOSFET & 1000,100 & Linear & Voltage & High & Positive & Very high \\
IGBT & 1200,400 & Linear & Voltage & Medium & Negative & High \\
MCT & 900,150 & Trigger & Voltage & Low & Negative & High \\
\hline
\end{tabular}

$\neq$ Positive at high current

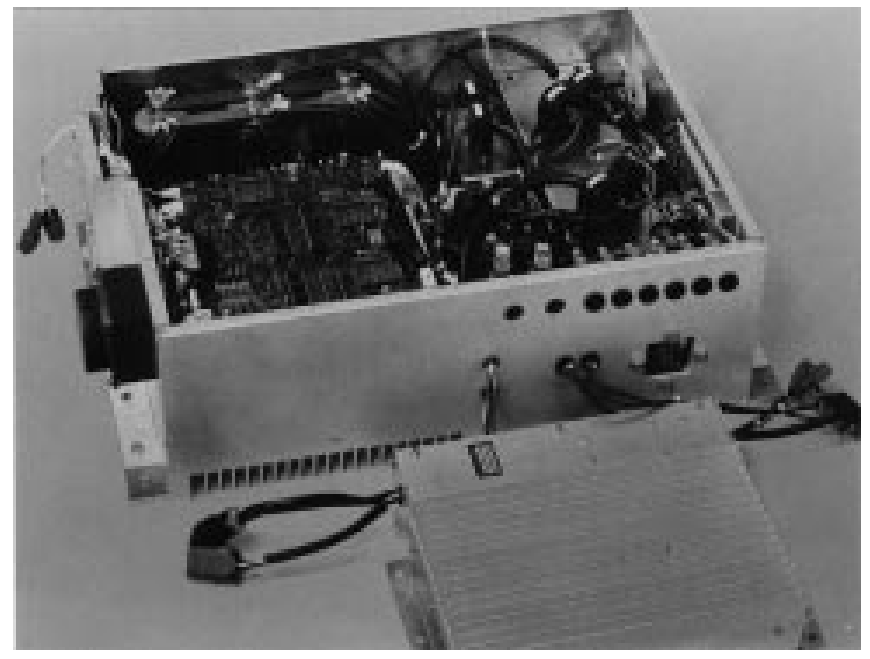

Fig. 6. Advanced IGBT-based inverter in Nissan FEV.

In addition to converter topologies, another important aspect of power converters is switching schemes. Starting from the last decade, numerous PWM switching schemes have been developed for battery-fed inverters, focusing on harmonic suppression, better utilization of dc-link voltage, suitability for real-time and microcontroller-based implementation, and tolerance of dc-link voltage fluctuation. These schemes can be classified as the voltage-controlled PWM and currentcontrolled PWM. The state-of-the-art voltage-controlled PWM schemes include the natural PWM, regular PWM, optimal PWM, delta PWM, and equal-area PWM. The state-of-the-art current-controlled PWM schemes include the hysteresis-band PWM, instantaneous current control with voltage PWM, and space vector PWM [38], [39]. On the other hand, the research on discrete pulse modulation (DPM) schemes for resonant dc-link inverters is becoming attractive.

\section{Electronic Controllers}

Conventional linear control such as PID can no longer satisfy the stringent requirements placed on high-performance EV's. In recent years, many modern control strategies such as model-referencing adaptive control (MRAC), self-tuning control (STC), variable structure control (VSC), fuzzy control, and neural network control (NNC) have been proposed. Both MRAC and STC have been successfully applied to EV propul- sion [24], [25]. Using sliding mode, VSC has also been applied to motor drives [40]. By employing emerging technologies of fuzzy logic and neural networks to realize the concept of intelligent controllers, fuzzy control and NNC have promising applications to EV propulsion.

In order to implement the aforementioned modern control strategies, powerful microelectronic devices are necessary. Modern microelectronic devices include microprocessors, microcontrollers, digital signal processors (DSP's), and transputers. Microprocessors are usually used to recognize the milestone of the development of microelectronics such as the 8086, 80186, 80286, 80386, 80486, and Pentium. Unlike microprocessors, which are the CPU of microcomputer systems, microcontrollers include all resources to serve as standalone single-chip controllers. Thus, microcontroller-based EV propulsion systems possess definite advantages of minimum hardware [41]. The state-of-the-art microcontrollers are the 8096, 80196, and 80960. DSP's such as the TMS32030, TMS32040, and i860 possess the capability of high-speed floating-point computation which is very useful to implement sophisticated control algorithms for high-performance EV propulsion systems. Transputers such as the T400, T800, and T9000 are particularly designed for parallel processing applications. By employing multiple chips of transputers, any sophisticated control algorithms can be implemented.

\section{BATTERY CHARgING}

The challenge of transforming EV's from concept to reality is to make it safe, convenient and easy for consumers to charge batteries. In order to improve convenience and increase charging efficiency, a number of charging schemes have been proposed: home charge, regenerative charge, solar charge, park-and-charge (PAC), and move-and-charge (MAC). Fig. 7 shows a typical multiple-charging system which aims to charge batteries using various charging schemes simultaneously.

As an EV is usually parked at home or a storage site at night, the battery charger in the vehicle can be connected into the domestic single-phase ac plug for slow nighttime charging. Depending on the battery capacity and depth of discharge, the charging time takes about 6-8 h, and the charging current is usually limited to $15 \mathrm{~A}$. This onboard charger should be less than $5 \mathrm{~kg}$. Thus, inexpensive, lightweight, and compact onboard battery chargers are essential for home charge. This 


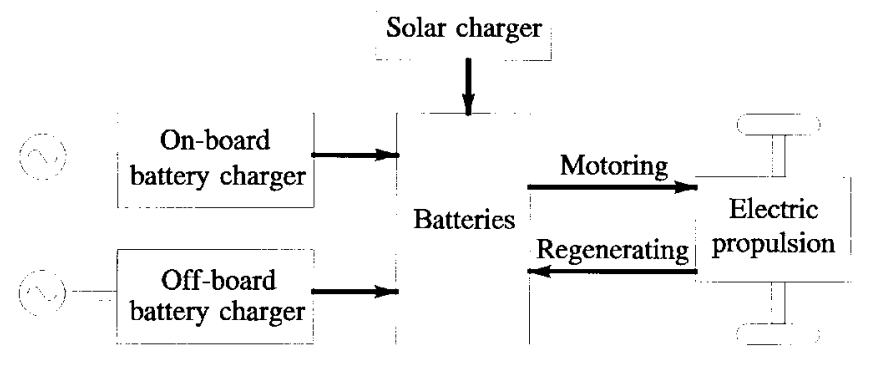

Fig. 7. Multiple charging system.

requirement stimulates the development of regulated ac-dc converters (controlled rectifiers) with high power density and high efficiency [42],[43]. As the electricity demand at night is relatively low, this home charging scheme can facilitate the load level control of power utilities.

During deceleration or downhill, the EV propulsion motor is operated as a generator to charge batteries through regenerative braking, so-called regenerative charge. Thus, multiquadrant $\mathrm{dc}$ choppers and full-bridge inverters are generally used for dc and ac propulsion systems, respectively. In the GM Impact 4, the regenerative braking system can extend the driving range by up to $25 \%$. In order to further enhance the use of energy, batteries can also be charged by solar energy using solar cells embedded in the vehicle roof. Typically, the solar cells are of the single-crystal silicon type and insulated from the vehicle cabin by using plastic. In the Nissan FEV, the $300 \mathrm{~V}$ solar cells provide conversion efficiency of $16 \%$ and are capable of fully charging up batteries in five weeks of fine weather.

When an EV is parked at a charging station, a microprocessor-controlled three-phase offboard battery charger initiates the power and effects its transfer to the vehicle. When an amount of parking time selected is insufficient to supply an amount of power selected using a normal charging scheme, the intelligent offboard charger allows for quick charge by continually adjusting the charging rate to match the ability of batteries to accept charge [44]. Moreover, charge equalization control can be employed to avoid overcharging batteries made up from long serial strings of cells and improve the life of batteries [45]. During quick charge, the charging current is generally over $100 \mathrm{~A}$ so that the charging time is about $20 \mathrm{~min}$ to attain $80 \%$ state-of-charge. This offboard charger weighs about $60 \mathrm{~kg}$. Thus, efficient three-phase ac-dc converters with high current capability are essential for this PAC system. The super-quick offboard charger for the Nissan FEV provides a charging current of 140 A to charge $40 \%$ of the battery capacity in $6 \mathrm{~min}$ and a full charge in as little as $15 \mathrm{~min}$ [46]. It should be noted that, from the power utility point of view, quick charge may not be desirable because it causes high peak power demand. An incentive-based electricity billing system may be employed to encourage people to charge batteries during off-peak periods while quick charge is encouraged only for emergency purposes at dedicated charging stations.
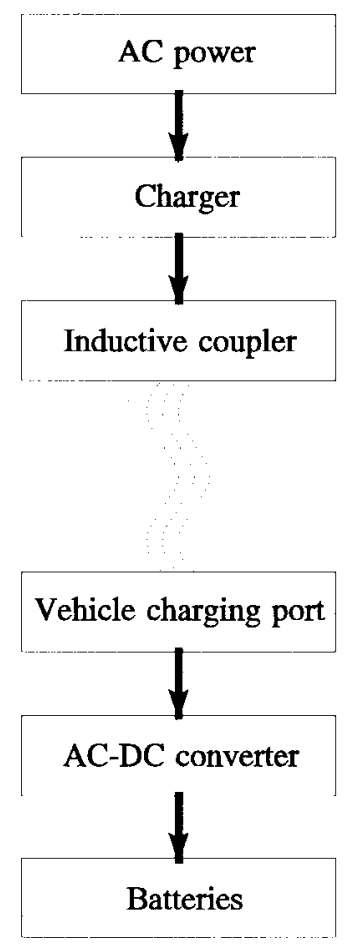

(a)

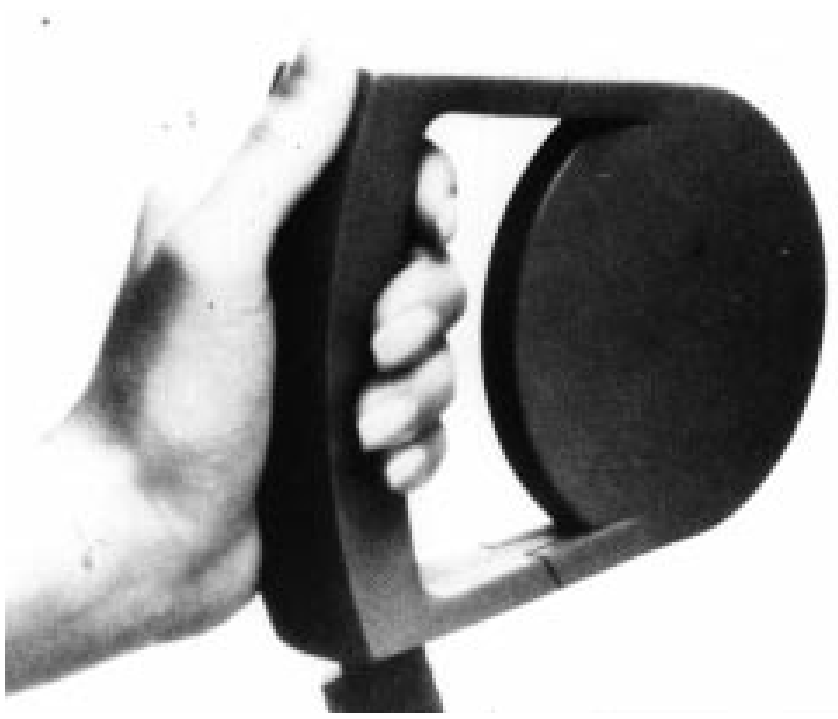

(b)

Fig. 8. Inductive charging. (a) Functional block diagram. (b) Inductive coupler.

Instead of using plugging-type power transfer, an inductive power transfer system has recently been developed for charging EV batteries [47]. As shown in Fig. 8, the inductive charging system developed by Hughes Power Control Systems features an inductive coupler with a coil that is completely encased in a plastic-covered paddle [48]. The vehicle is equipped with a charging port that also incorporates a coil. When the paddle is inserted into the charging port, the corresponding magnetic fields intermingle to complete the circuit. The incoming power is then converted by an ac-dc converter to charge batteries. This inductive charging system is inherently safe under all-weather operation-tolerant of 
water, snow, ice, dirt, and dust particles. In order to have a lightweight and compact inductive charging port, low-mass magnetic cores and a high-frequency ac-dc converter are necessary. Typically, this system can handle power levels from $1.5-25 \mathrm{~kW}$ with overall efficiency of better than $90 \%$, while the power transfer frequency is $40-350 \mathrm{kHz}$.

The most ideal situation for charging EV batteries is to perform the charge while the vehicle is cruising on the road-so-called MAC. Thus, the driver does not need to find a charging station, park the vehicle, and spend a relatively long time to charge the batteries. This MAC system is embedded on the surface of a section of highway, the charging zone, and does not need any additional space. Both contact and inductive types of MAC can be implemented. For the contacttype MAC system, an onboard contact arch is mounted on the bottom of the EV body. By physically contacting the charging elements which have been embedded on the road surface, the arch picks up instantaneous high current. Since the EV is cruising through the charging zone, the charging process is so-called pulse charge. For the inductive-type MAC system, the onboard contact arch is replaced by inductive coils and the charging elements are replaced by high-current coils which produce strong magnetic field.

By estimating the present number of gas stations for gasoline-powered vehicles, the demand on battery charging stations for EV's must be enormous. Thus, the development of battery chargers, virtually ac-dc converters, plays a very important role for preparing the charging infrastructure of EV's [49].

\section{POWER ACCESSORIES}

Because EV's do not have an alternator, many auxiliary systems must depend on EV batteries to supply the necessary power. Air conditioning, power steering, lamps, and radios are just some of the accessories of an EV which have to rely on various power converters to provide power from batteries.

\section{A. Temperature Control Unit}

The experience with compressor-driven air-conditioning units in gasoline-powered vehicles encourages the use of electrically driven units in EV's. The rotary-compressor air-conditioning unit in EV's is powered directly by a dedicated variable-speed motor. This air conditioning unit is of the heating/cooling type as it incorporates a heat pump to provide the heating function. The major features of this unit include the inverter drive, quiet operation assured by effective vibration control, and energy savings achieved through the use of thermal-insulated glass that reduces the load on the air-conditioning unit. To minimize penalties to EV driving range and performance, the power consumption and weight of the unit must be low. Thus, efficient and low weight inverter drives of several kilowatts with low acoustic noise are desirable. It should be noted that, due to leakage and hose permeation, emissions of refrigerant such as CFC-12 contribute to stratospheric ozone depletion and global warming. Air-conditioning units intended for EV's should use an environmentally acceptable refrigerant such as HFC-134a [50].

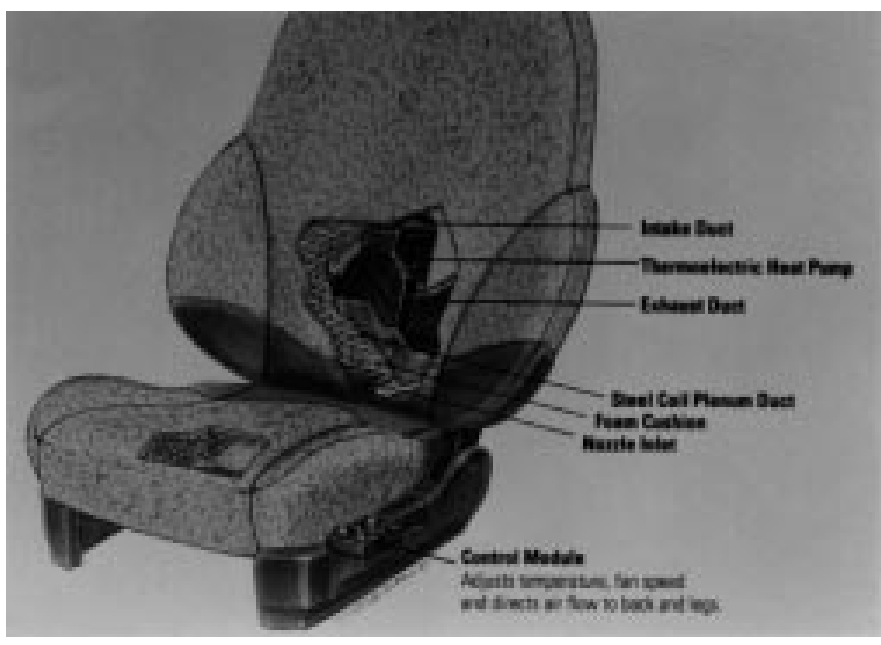

Fig. 9. Variable temperature seat in U2001.

Recently having been used in the U2001, the thermoelectric variable temperature seat (VTS) developed by Amerigon (Fig. 9) is a highly energy-efficient means of providing vehicle occupant heating and cooling [51]. A typical energy requirement for the VTS is $100 \mathrm{~W}$ per occupant compared with 1-4 $\mathrm{kW}$ per vehicle for a standard automotive air-conditioning unit. Since the energy requirement of an existing air-conditioning unit may reduce the driving range of an EV by $20 \%-30 \%$, this energy-efficient VTS is particularly suitable for an EV. The high energy efficiency of the VTS is achieved by using heating and cooling energy to directly heat and cool the occupant rather than to heat and cool the surrounding space and interior vehicle surfaces. The temperature effect is produced by a combination of conduction to the occupant through the seatrest and backrest and through convection of conditioned air escaping through the surface of the seat. Since heating and cooling are provided by a thermoelectric heat pump and blower contained within the seat, it contains no refrigerants, hence, environmental friendliness. This new idea stimulates the development of efficient, lowweight, and compact thermoelectric heat pumps and blowers.

\section{B. Power Steering}

In order for power steering to be feasible in EV's, extremely efficient high-power controllers are necessary to provide needed performance without sapping precious battery reserves. Recently, an adaptable inverter fitting most threephase ac induction motors has been developed for power steering [52]. A DSP is employed to perform VVVF control. When load is minimal, the power steering unit measures input power, estimates the load, and adjusts the volts/hertz amplitude accordingly, thus decreasing power dissipation. At maximum power levels, the DSP uses a PID control algorithm to regulate input power and provide pump pressure limiting. The input power of this unit is about $900 \mathrm{~W}$.

\section{Auxiliary Power Converter Unit}

An auxiliary power converter (APC) unit is used to convert battery power into regulated power for all vehicle accessories. These power accessories include power seats, power windows, power antenna, power door locks, brake vacuum pumps, 


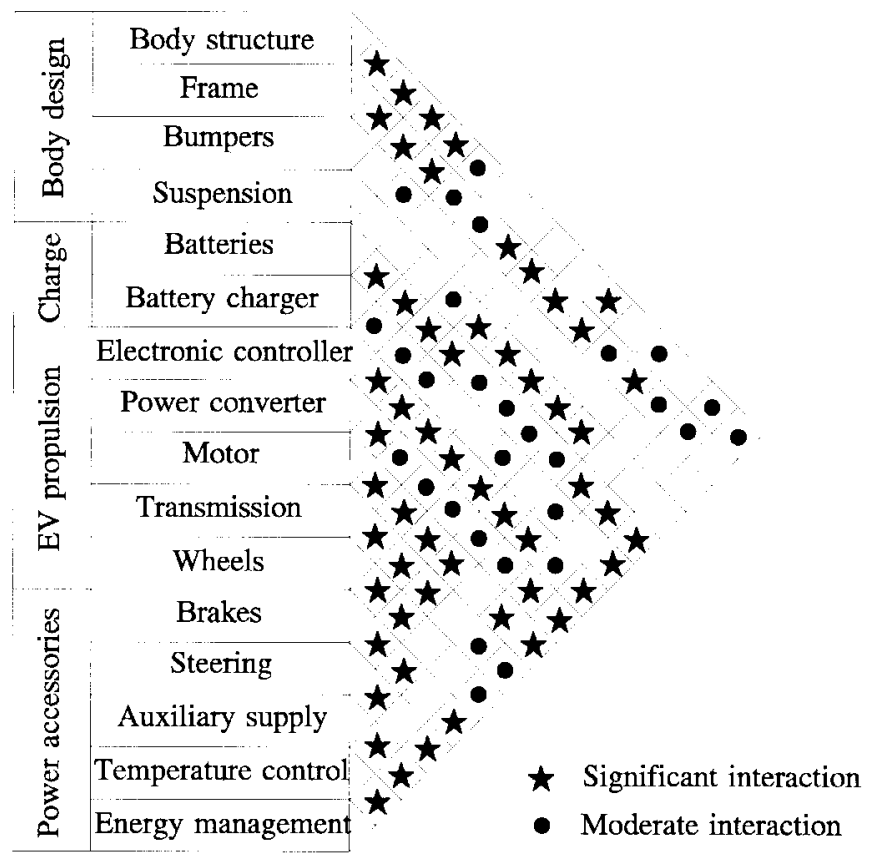

Fig. 10. EV sub-system interactions.

radios, windshield defoggers, de-icers, headlamps, air bags, CRT display, and the EMS. Although most of them are operated at $12-\mathrm{V} \mathrm{dc}$, some accessories require $47-\mathrm{V}$ dc power. This is usually accomplished by using a full-bridge PWM dc-dc converter. In order to reduce heat sinking requirement and improve operating performance, the converter is operated at high frequency and under ZVS condition. Thus, this unit can run reliably with inexpensive forced-air cooling. Typically, the output power of this unit is about $1.6 \mathrm{~kW}$.

\section{SySTEM INTEGRATION}

Due to the multidisciplinary nature of EV's, the process of identifying the preferred features and packaging options for system integration should be carried out at the system level. Fig. 10 illustrates typical subsystem interactions in EV's. The impact of these subsystem interactions affects the vehicle cost, performance, and safety.

\section{CONCLUSIONS}

This paper has reviewed the current status of multidisciplinary technologies in EV's with emphasis on power electronics for EV propulsion, battery charging, and power accessories. It indicates that power electronics technology plays a very important role in the development of EV's. As the EV market will be expanding dramatically in the coming years, research activities on power electronics technology for EV's must be highly attractive.

\section{REFERENCES}

[1] "Air pollution-transportation linkage," California Air Resources Board Office of Strategic Planning, 1989.

[2] L. G. O'Connell, "Electric vehicles: A clean, energy-efficient urban transportation alternative," EPRI Rep., vol. 30, no. 5, Sept./Oct. 1991.

[3] “2001: US electric vehicle sales," Elec. Propulsion, vol. 6, no. 4, p. 2, 1991.
[4] W. W. Burns, III, "Power electronics-Keeping pace with society," IEEE Trans. Power Electron., vol. PE-1, pp. 1-2, 1986.

[5] M. Nishihara, "Power electronics diversity," in Proc. Int. Power Electronics Conf., 1990, pp. 21-28.

[6] C. C. Chan and K. T. Chau, "Electric vehicle technology-An overview of present status and future trends in Asia and Pacific areas," in Proc. Int. Electric Vehicle Symp., 1992, no. 1.02.

[7] M. J. Riezenman, "Electric vehicles," IEEE Spectrum, vol. 29, no. 11, pp. $18-21,1992$.

[8] C. C. Chan, "An overview of electric vehicle technology," Proc. IEEE, vol. 81, pp. 1202-1213, Sept. 1993.

[9] D. Woodruff, L. Armstrong, and J. Carey, "Electric cars," Int. Bus. Week, pp. 36-40, May 30, 1994.

[10] C. C. Chan and K. T. Chau, "Power electronics challenges in electric vehicles," in Proc. IEEE Int. Conf. Industrial Electronics Contr. Instrum., 1993, pp. 701-706.

[11] P. Terpstra, 1992 Electric Vehicle Directory. Spirit Pub., 1992.

[12] F. A. Wyezalek, "GM electric vehicle technology," in Proc. Int. Symp. Automotive Technology Automation, 1991, pp. 271-277.

[13] N. Irie, M. Fukino, and H. Horie, "Nissan FEV-A new concept electric vehicle," in Proc. Int. Electric Vehicle Symp., 1992, no. 13.02.

[14] K. Faust, A. Goubeau, and K. Scheuerer, "Introduction to the BMWE1," SAE SP-915, pp. 33-40, 1992.

[15] W. H. Deluca, A. F. Tummillo, J. E. Kulaga, C. E. Webster, K. R. Gillie, and R. L. Hogrefe, "Performance evaluation of advanced battery technologies for electric vehicle applications," in Proc. Intersoc. Energy Convers. Eng. Conf., 1990, pp. 314-319.

[16] T. Moore, "The push for advanced batteries," EPRI J., pp. 17-19, 1991

[17] A. Hiny, Battery R\&D Report. Power Sources Manuf. Assoc. Pub., 1992.

[18] D. Coates and L. Miller, "Advanced batteries for electric vehicle applications," in Proc. Int. Electric Vehicle Symp., 1992, no. 14.03.

[19] W. A. Adams, W. Fell, G. S. Song, and M. Walker, "Consideration of aluminum/air and zinc/bromine flow batteries as EV range extenders," in Proc. Int. Electric Vehicle Symp., 1992, no. 18.02.

[20] M. J. Riezenman, "The great battery barrier," IEEE Spectrum, vol. 29, no. 11 , pp. $97-101,1992$

[21] T. J. E. Miller, Brushless Permanent-Magnet and Reluctance Motor Drives. London, U.K.: Oxford Univ. Press, 1989

[22] C. C. Chan and K. T. Chau, "Advanced ac propulsion systems for electric vehicles," in Proc. Int. Symp. Automotive Technology Automation, 1991, pp. 119-125.

[23] C. C. Chan and W. C. Lo, "Control strategy of PWM inverter drive system for electric vehicles," IEEE Trans. Ind. Electron., vol. 34, pp. 447-456, 1987

[24] C. C. Chan, W. S. Leung, and C. W. Ng, "Adaptive decoupling control of induction motor drives," IEEE Trans. Ind. Electron., vol. 37, pp. 41-47, 1990.

[25] C. C. Chan, W. S. Leung, and K. T. Chau, "A new permanent magnet motor drive for mini electric vehicles," in Proc. Int. Electric Vehicle Symp., 1990, pp. 165-174.

[26] C. C. Chan, J. Z. Jiang, G. H. Chen, and K. T. Chau, "Computer simulation and analysis of a new polyphase multipole motor drive," IEEE Trans. Ind. Electron., vol. 40, pp. 570-576, 1993.

[27] C. C. Chan, J. Z. Jiang, G. H. Chen, X. Y. Wang, and K. T. Chau, "A novel polyphase multipole square-wave permanent magnet motor drive for electric vehicles," IEEE Trans. Ind. Applicat., pp. 1258-1266, 1994.

[28] S. J. Salon, "Finite element analysis of electric machinery," IEEE Comput. Appl. Power Mag., pp. 29-32, April 1990.

[29] C. C. Chan, L. Yan, P. Chen, Z. Wang, and K. T. Chau, "Analysis of electromagnetic and thermal fields for induction motors during starting," IEEE Trans. Energy Conv., vol. 9, pp. 53-60, 1994.

[30] C. C. Chan and K. T. Chau, "Computer graphics aided design for an advanced electrical motor," IEEE Trans. Computer-Aided Design, vol. 7, pp. 72-74, 1990.

[31] _ "Finite element method based electrical machine design using distributed computing," Comput. Ind., vol. 17, no. 4, pp. 367-374, 1991.

[32] Nissan FEV. Nissan Pub., 1992.

[33] J. M. Hillhouse, "EV's down under-Electric vehicles in mining," in Proc. Int. Electric Vehicle Symp., 1990, pp. 940-949.

[34] T. Sakurai, K. Natori, and N. Fujiwara, "R\&D activities on electric vehicles in TEPCO," in Proc. Int. Electric Vehicle Symp., 1992, no. 2.01 .

[35] M. Fracchia, T. Ghiara, and M. Marchesoni, "Generalized design of power converters for electric vehicle," in Proc. Int. Electric Vehicle Symp., 1992, no. 16.01 .

[36] B. K. Bose, Modern Power Electronics Evolution, Technology, and Applications. Piscataway, NJ: IEEE Press, 1992. 
[37] R. D. King, J. N. Park, A. W. Clock, and D. L. Watrous, "ETX-II 70 hp MCT inverter electric drive system performance tests," SAE SP-915, pp. 41-46, 1992.

[38] C. C. Chan and K. T. Chau, "A new PWM algorithm for battery-source three-phase inverters," Elec. Machines Power Sys., vol. 19, no. 1, pp. 43-54, 1991.

[39] J. Holtz, "Pulsewidth modulation-A survey," IEEE Trans. Ind. Electron., vol. 39, pp. 410-420, Oct. 1992.

[40] V. I. Utkin, "Sliding mode control design principles and applications to electric drives," IEEE Trans. Ind. Electron., vol. 40, no. 1, pp. 23-36, 1993.

[41] C. C. Chan and K. T. Chau, "A novel PWM algorithm for single-chip microcomputer-based three-phase inverter," in Proc. Int. Conf. Power Electronics Motor Controllers, 1990, pp. 445-449.

[42] C. C. Chan, W. S. Leung, and K. C. Chu, "A microprocessor based intelligent battery charger for electric vehicle lead acid batteries," in Proc. Int. Electric Vehicle Symp., 1990, pp. 456-466.

[43] Y. Gao, "A bus system controlled $10 \mathrm{~kW}$ battery charger with IGBT," in Proc. Int. Electric Vehicle Symp., 1992, no. 20.01.

[44] J. K. Nor, "Fast charging advances the art of refueling electric vehicles,' in Proc. Int. Symp. Automotive Technology Automation, 1991, pp. 65-72.

[45] S. T. Hung, D. C. Hopkins, and C. R. Mosling, "Extension of battery life via charge equalization control," IEEE Trans. Ind. Electron., vol. 40, pp. 96-104, 1993.

[46] M. Fukino, N. Irie, and H. Ito, "Development of an electric concept vehicle with a super quick charging system," SAE SP-915, pp. 23-32, 1992.

[47] R. J. Risser, C. A. Haslund, and J. G. Bolger, "Inductive charging of electric vehicles: Testing and evaluation of an automated system," in Proc. Int. Electric Vehicle Symp., 1992, no. 20.02.

[48] "Electric vehicle chargers, Hughes Power Control Systems, CA, 1992.
[49] C. A. Bleijs and J. L. Mazoyer, "Preparing the infrastructure for the charging of tomorrow's electric cars," in Proc. Int. Electric Vehicle Symp., 1992, no. 9.02 .

[50] J. Dieckmann and D. Mallory, "Variable speed compressor, HFC-134a based air conditioning system for electric vehicles," SAE SP-915, pp. 87-91, 1992

[51] "Thermoelectric variable temperature seats," Amerigon, 1992.

[52] "Electric vehicle power accessories," Hughes Power Control Systems, CA, 1992.

C. C. Chan (M'77-SM'77-F'92), for a photograph and biography, see this issue, p. 2.

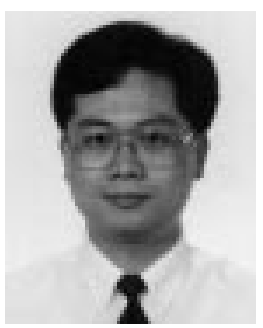

K. T. Chau (M'89) received the B.Sc.(Eng.) (firstclass honors), M.Phil., and Ph.D. degrees in electrical and electronic engineering from the University of Hong Kong in 1988, 1991, and 1993, respectively.

From 1990 to 1994, he worked as a Lecturer in the Department of Electrical Engineering at the Hong Kong Polytechnic University. Since 1995 he has been with the Department of Electrical and Electronic Engineering, University of Hong Kong. His research interests include advanced motor drives, electric vehicles, and power electronics. He has published more than 50 refereed technical papers and several industrial reports. 